\title{
The black hole and the entropy collector
}

\author{
Hope on the horizon.
}

W ilbert Zolnierczyk had reached the end of the line, although in his case the line was actually the curve of a black hole's space-time warp. Moments after arriving near the black hole, his ship's com crackled.

"I am Zebulon," a voice announced.

Wilbert scanned the Skipstone's vicinity: nothing except distinctly non-sentient intergalactic dust - and the black hole.

Frowning, Wilbert said: "Err, Zebulon, nice to meet you. Are you ... a black hole?"

"I prefer the term no-drama, apparenthorizon gravastar," Zebulon replied. "Super high-gravity location is also acceptable."

Wilbert studied his instruments. "How are we able to communicate?"

"I've programmed your computer with a Hawking radiation dictionary."

"Wow." Wilbert wasn't sure what else to say. "How did you become self-aware?"

"A ship carrying an inter-dimensional being once fell into me. Part of the being remained trapped within, while part passed through me, into another Universe."

Wilbert perked up. "Another Universe? Zebulon, that's exactly what I'm looking for - a gateway between worlds."

There was a pause. "I may be able to offer you safe passage," Zebulon said. "In exchange for something."

"Like what?"

"I'll be honest - I have terrible impulse control and basically eat anything. Truth be told, I wish I could stop. Have you seen my horizon?” Zebulon sounded depressed. "Once I talked to a psychiatrist about my problem. Right before I gulped down her ship, she told me I had a singularity complex."

"Oh dear," Wilbert said. "Well, I'm not sure my cargo will interest you. I'm an entropy collector."

"You're talking to someone whose entropy is proportional to the surface area of their horizon, remember? Of course I'm interested.

$\rightarrow$ NATURE.COM

Follow Futures: y @NatureFutures f go.nature.com/ mtoodm

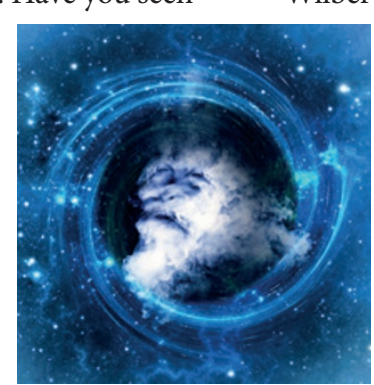

disposal outfits the demand is, uh, admittedly thin. That's why I'm here. I've decided to start my life over in another Universe, one in which the second law of thermodynamics runs backwards, making my entropy collection valuable. You could help me get there."

"So you not only want safe passage through my nexus, but for me to spit you out into the right Universe, too? How much entropy are you offering?"

"As entropic units are a bit abstract, I've devised my own measurement system: antiJerry's, where one anti-Jerry is defined as enough entropy to disorganize an otherwise perfectly neat, one-bedroom Upper West Side apartment back on Earth. My neutronium microcontainers hold 42 antiJerry's apiece. I could give you 10 containers."

The com was quiet for a long time. "Very well," Zebulon said at last.

"I'll deliver them once I'm safely on the other side. Agreed?"

"Agreed. Sending you entry vectors now."

The Skipstone's computer received the data. "I'm ready," Wilbert said. "I just want to point out that if, for whatever reason, all the entropy aboard my ship were released into you at once, you'd evaporate away."

"I understand."

"Course plotted. Engines activated."

Once the Skipstone drifted past the horizon a spiralling stream of metal and body fragments coruscated near the ship's viewer. Faces frozen in horror seemed to stare at Wilbert with recriminatory eyes. Everything twinkled with a beautifully eerie glow. "Don't mind that, just a collapsing generation starship," Zebulon said.

Wilbert swallowed. "How long will it take them to ...?"

"Forever," Zebulon said. "The closer they get to my singularity, the more time slows down for them. One of those pesky paradoxes."

As the descent continued, Wilbert saw something even more startling: was that the face of his uncle Dave, the one who had lived on Carlin IV? Uncle Dave, or his lookalike, floated serenely in space and appeared to be holding a lottery ticket in his frozen right hand. Wilbert waved goodbye to him as the ship plummeted ever deeper.

After what may have been an actual eternity, the Skipstone emerged into regular space.
"Phew." Wilbert wiped his brow. "Thank you for making good on your word, Zebulon. Here's my payment."

He released the entropy containers into the void and rubbed his hands in anticipation of his new life.

But something was wrong. Zebulon was silent, and the ejected goods weren't falling into him. Instead, they drifted partway stopped and then reversed course, floating back towards the ship.

Entropy running backwards, Wilbert thought, means the arrow of time is pointing the other way -

- just took a few seconds -

- to kick in.

Then he figured it out all over again:

- In kick to -

- seconds few a took just -

- way other the pointing is time of arrow the means -

- backwards running entropy.

Wilbert rubbed his hands in anticipation of his new life and absorbed the entropy containers into the ship.

"Payment my here's. Zebulon, word your on good making for you thank." Wilbert wiped his brow. "Phew."

And then he entered the black hole once more, now from the time-reversing side.

Wilbert found himself heading straight towards the singularity. The Skipstone's controls no longer responded, and the cabin got cold.

"What's happening?" Wilbert cried out.

"Your life-support systems are failing," Zebulon observed.

"Why?" Wilbert asked, horrified. As the ship's components broke down one by one, the entropy containers leaked out their contents, further accelerating the disintegration.

"Why?" Zebulon mocked. "I'm a black hole, that's why. It's in my nature. Poor impulse control, remember?"

"But we both could have been happy -"

The Skipstone was crushed into oblivion, never to skip among the stars again.

Then Zebulon disappeared into non-being. All that remained in his place was a vague metaphysical whiff of poor self-esteem.

ALVARO ZINOS-AMARO is co-author, with Robert Silverberg, of When the Blue Shift Comes. His short fiction has previously appeared in Nature, Analog and Galaxy's Edge. 